\title{
Agents with inotropic properties for the management of acute heart failure syndromes. Traditional agents and beyond
}

\author{
John R. Teerlink • Marco Metra • Valerio Zacà • \\ Hani N. Sabbah • Gadi Cotter • Mihai Gheorghiade • \\ Livio Dei Cas
}

Published online: 30 October 2009

(C) The Author(s) 2009. This article is published with open access at Springerlink.com

\begin{abstract}
Treatment with inotropic agents is one of the most controversial topics in heart failure. Initial enthusiasm, based on strong pathophysiological rationale and apparent empirical efficacy, has been progressively limited by results of controlled trials and registries showing poorer outcomes of the patients on inotropic therapy. The use of these agents remains, however, potentially indicated in a significant proportion of patients with low cardiac output, peripheral hypoperfusion and end-organ dysfunction caused by heart failure. Limitations of inotropic therapy seem to be mainly related to their mechanisms of action entailing arrhythmogenesis, peripheral vasodilation, myocardial ischemia and damage, and possibly due to their use in patients without a
\end{abstract}

\section{J. R. Teerlink}

Section of Cardiology, San Francisco Veterans Affairs Medical Center, University of California, San Francisco, San Francisco, CA, USA

\section{Metra $(\bowtie) \cdot$ L. D. Cas}

Cardiology, Department of Experimental and Applied Medicine, University of Brescia, c/o Spedali Civili di Brescia,

Piazza Spedali Civili 1, 25123 Brescia, Italy

e-mail: metramarco@libero.it

V. Zacà

Division of Cardiology, Cardiovascular and Thoracic

Department, Santa Maria alle Scotte Hospital, Siena, Italy

H. N. Sabbah

Department of Medicine, Division of Cardiovascular Medicine, Henry Ford Heart \& Vascular Institute, Detroit, MI, USA

G. Cotter

Momentum Research, Durham, NC, USA

M. Gheorghiade

Feinberg School of Medicine, Northwestern University,

Chicago, IL, USA clear indication, rather than to the general principle of inotropic therapy itself. This review will discuss the characteristics of the patients with a potential indication for inotropic therapy, the main data from registries and controlled trials, the mechanism of the untoward effects of these agents on outcomes and, lastly, perspectives with new agents with novel mechanisms of action.

Keywords Acute heart failure - Advanced chronic heart failure - Inotropic agents · Prognosis · Istaroxime · Omecamtiv mecarbil

\section{Introduction}

Since the introduction of digoxin into clinical practice, inotropic agents have played a pivotal role in the treatment of heart failure (HF). Enthusiasm, based on the pathophysiological rationale for their administration, has been progressively limited by the results of clinical research with controlled trials and registries showing that their administration may be attended by untoward effects and increased mortality. This has led to a radical reassessment of their role in the treatment of HF. Agents with novel mechanisms of action are currently being tested, and further improvements are likely to occur [1-6].

\section{"Epidemiology" of inotropic agents in acute heart failure}

Uncertainties regarding the indications and the benefits of inotropic agents in HF are consistent with differences in their use. Data from registries show a wide variability in the prescription rates of inotropic drugs. The proportion of patients receiving them ranges from $7 \%$,in the registry from the Organized Program to Initiate Lifesaving Treatment in 
Hospitalized Patients with Heart Failure (OPTIMIZE-HF) [7], to nearly 25\% in the EuroHeart Failure Survey II (EHFS II) [8] and in an Italian registry [9].

It is also interesting to note that the administration of inotropic agents often does not comply with current indications and guidelines [10-13]. In the Acute Decompensated Heart Failure National Registry (ADHERE), intravenous inotropic agents were administered to $8 \%$ of patients with acute HF and preserved left ventricular (LV) systolic function (versus 19\% of the patients with reduced LV systolic function) [14]. Low systolic blood pressure is currently considered as a major criterion for selection of patients for inotropic treatment. Despite this, inotropic agents are often administered to patients with normal or even high blood pressure. Among the 48,612 patients enrolled in the OPTIMIZE-HF, $6.5,4.5$ and $3.2 \%$ were treated with an inotropic agent in the systolic blood pressure quartiles of $120-139 \mathrm{mmHg}, 140-161 \mathrm{mmHg}$ and $>161 \mathrm{mmHg}$, respectively [7]. In ADHERE, only 8\% of the total patients receiving inotropes had a systolic blood pressure $<90 \mathrm{mmHg}$, and the systolic blood pressure on admission were $121 \pm 27 \mathrm{mmHg}$ and $124 \pm 29 \mathrm{mmHg}$ in the patients receiving dobutamine and milrinone, respectively [15]. Data from the EHFS II indicate that over $4 \%$ of patients with hypertensive HF (with high BP defined as $>180 / 100 \mathrm{mmHg}$ ) received dobutamine or dopamine [8]. Thus, intravenous inotropic agents are still administered to a significant proportion of patients admitted for acute HF, but some of these patients may not have needed them.

\section{Indications to inotropic agents}

In theory, inotropic agents improve hemodynamic parameters, increasing cardiac output and reducing left and right ventricular filling pressure, through direct enhancement of myocardial contractility. Accordingly, they are indicated for the treatment of patients with both peripheral hypoperfusion and fluid retention caused by impaired cardiac contractility. Other criteria may be necessary to have an indication for inotropic therapy (Table 1). First, hemodynamic impairment must be present despite optimal medical treatment including neurohormonal antagonists, diuretics and vasodilators. Second, this hemodynamic impairment must be "clinically meaningful", i.e. causing symptoms, clinical signs and, more importantly, end-organ (kidney, liver) dysfunction. When this occurs, it may be hypothesized that a correction of hemodynamic abnormalities through inotropic therapy may also favorably affect patient outcomes.

The indication for the appropriate administration of inotropic agents requires that peripheral perfusion be adequately assessed either by invasive hemodynamic monitoring or, more frequently, by clinical examination. Clinical signs are generally relatively accurate for the assessment of fluid overload. In contrast, peripheral hypoperfusion is more difficult to detect. Hypotension is the most frequently used and, ultimately, the best marker for hypoperfusion and low cardiac output. Other signs of hypoperfusion include a reduced pulse pressure, sleepy or obtunded sensorium, cool extremities, hyponatremia, laboratory signs of renal and/or hepatic dysfunction and hemodynamic intolerance to angiotensin converting enzyme (ACE) inhibitors and beta-blockers [16, 17].

These indications are in agreement with current guidelines. In the American College of Cardiology Federation (ACCF)/American Heart Association guidelines, inotropic agents are indicated to improve symptoms and end-organ function in patients with low output syndrome, LV systolic dysfunction and systolic blood pressure $<90 \mathrm{mmHg}$ despite adequate filling pressure [13]. In the ESC guidelines, patients with acute HF are stratified on the basis of their systolic blood pressure at presentation, and inotropic agents are indicated in patients with values $\leq 100 \mathrm{mmHg}$ [12].

These indications, based on clinical assessment and systolic blood pressure values, clearly limit the use of currently available intravenous inotropic agents only to those patients most likely to benefit from their administration. Values of systolic blood pressure $<90-100 \mathrm{mmHg}$ have been reported in less than $10 \%$ of the patients with acute HF syndromes (AHFS) [7, 8, 15]. These patients have increased in-hospital and postdischarge mortality rates with a strong inverse correlation between systolic blood pressure and survival [7]. The odds ratio (OR) of in-hospital death increased by $21 \%$ for each $10-\mathrm{mmHg}$ decrease in systolic

Table 1 Indications for inotropic therapy

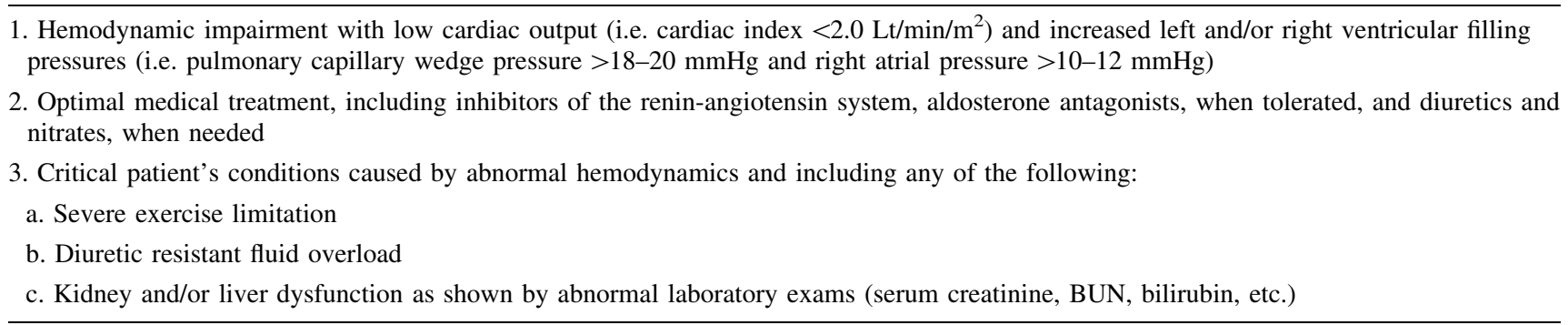


blood pressure below $160 \mathrm{mmHg}$ in the OPTIMIZE-HF registry [7], and in-hospital mortality rate was nearly $40 \%$ among patients admitted in cardiogenic shock in the EHFS II $(3.9 \%$ of total), a greater than sixfold increase in risk when compared to any other clinical profile of AHFS [8].

The criteria outlined previously apply to patients hospitalized for acute HF. However, an indication for inotropic therapy may also be found in outpatients with HF who have persistent severe symptoms, frequent hospitalizations caused by episodes of fluid retention and/or peripheral hypoperfusion and/or signs of hepatic or renal dysfunction. These patients include those in class IV of the New York Heart Association (NYHA) classification as well as in stage $\mathrm{D}$ of the ACCF/AHA classification [18]. Inotropic agents may be indicated as bridge to heart transplantation or mechanical assist device implantation or as palliation for symptoms in end-stage HF [11-13, 19].

The recently introduced Interagency Registry for Mechanically Assisted Circulatory Support (INTERMACS) has been developed to improve classification of patients with advanced HF with potential indications to mechanical circulatory support. Seven clinical profiles have been described, from advanced NYHA class III symptoms to cardiogenic shock, with 3 modifiers (arrhythmias, need of temporary circulatory support and frequent hospitalizations or emergency visits). Continuous intravenous administration of inotropic agents is a hallmark of the 3 highest levels of severity, currently including $80 \%$ of the patients on mechanical circulatory support [20]. This registry, as well as the HFA-ESC position statement [18], highlights the need of therapies to support the failing heart through either medical therapy or mechanical supports.

\section{Prognostic impact and limitations of traditional inotropic agents}

Aims of treatment of patients with AHFS have been extensively discussed in the last years. Radical changes occurred and criteria for approval of new agents in AHFS are now not very different from those for drugs for chronic HF. Aims of treatment include an improvement in symptoms and/or outcomes [6, 10-13, 21]. Any new agent cannot be approved in the absence of data showing its lack of untoward effects on outcomes. However, most of the current therapy for acute HF is based on drugs approved in the past only on the basis of short-term hemodynamic and/ or symptomatic benefits that, as is the case of traditional inotropic agents, have been often associated with untoward effects on outcome. We will report herewith data regarding the effects of inotropic agents on outcomes in patients with either acute or advanced chronic HF and the potential mechanisms of these untoward effects.
Acute heart failure: retrospective analyses

As is the case with most of the agents currently used for the treatment of AHFS, inotropic agents are now used in clinical practice despite the absence of data regarding their effects on outcomes obtained by prospective, randomized controlled studies. Thus, their relation with outcomes has been mainly studied in retrospective analyses of registries. Abraham et al. [22] have assessed the role of intravenous therapy on inhospital mortality in 15,230 patients with AHFS studied in the ADHERE registry. Inotropic therapy was associated with a twofold increase in the risk of in-hospital mortality when compared to treatment with vasodilators. In-hospital mortality rates were 12.3 and $13.9 \%$ in patients receiving milrinone or dobutamine versus 4.7 and $7.1 \%$ in those receiving nitrates or nesiritide, respectively [22]. The increased risk associated with inotropic therapy remained significant after adjustment for demographics and baseline clinical characteristics by propensity score analysis.

Inotropic therapy also had an independent association with an increased risk of in-hospital mortality in other registries [7, 9]. In the Evaluation Study of Congestive Heart Failure and Pulmonary Artery Catheterization Effectiveness (ESCAPE) trial, the administration of inotropic agents was associated with an increase in 6-month risk of death and of deaths or rehospitalizations (adjusted OR, 2.14, 95\% CI: $1.10-4.15, \quad P=0.04$; and $1.96,95 \%$ CI: $1.37-2.82$, $P<0.001$, respectively). Patients with the worst outcomes were those receiving both inotropes and vasodilators (adjusted OR, 4.81, 95\% CI: 2.34-9.90, $P<0.001$ ) [23].

The association between inotropic therapy and increased mortality found in retrospective analyses may have different causes, in addition to direct untoward effects of these agents on outcomes. First, although these associations remained significant after adjustment for demographic and baseline clinical variables by multivariable analysis, it cannot be excluded that inotropic agents were administered to the most severely ill patients. This selection bias may not be adequately eliminated by statistical methods. For example, in ADHERE, the median time to initiation of inotropic therapy was of $18 \mathrm{~h}$, compared with $1.3 \mathrm{~h}$ with nitrates. This indicates that inotropes were often used as rescue therapy in patients not responding to the other agents and, thus, in more severe patients than those receiving vasodilators [22]. Second, there may have been a poor selection of patients treated with inotropes. As pointed out before, a low systolic blood pressure is now considered a main criterion for the indication to inotropic therapy. However, a systolic blood pressure $<90 \mathrm{mmHg}$ was present in only $8 \%$ of the patients receiving either dobutamine or milrinone in ADHERE [15], and only 1,404 of 2,613 patients $(54 \%)$ on inotropes had a systolic blood pressure $<120 \mathrm{mmHg}$ in OPTIMIZE-HF [7]. It must, however, be 
noted that the increase in mortality associated with inotropic therapy was found in all systolic blood pressure quartiles patients groups, independent of blood pressure in this registry [7].

Acute heart failure: prospective studies

Small, placebo-controlled studies have shown hemodynamic and symptomatic improvements with a tendency toward higher mortality risk after administration of either dobutamine or phosphodiesterase type 3 inhibitors (PDE3I); such as amrinone, milrinone and enoximone) [23]. Results from small placebo-controlled trials with betaagonists, including dobutamine, and PDE3-I have been combined in a meta-regression analysis showing a tendency to an increase in mortality associated with dobutamine or high-dose dopamine (OR 1.50, 95\% CI: 0.51-3.92) or PDE3-I [24].

In the Outcomes of a Prospective Trial of Intravenous Milrinone for Exacerbations of Chronic Heart Failure (OPTIME-CHF) trial, 951 patients admitted for exacerbation of chronic HF caused by LV systolic dysfunction were randomized to a 48-hour infusion of either milrinone or placebo on top of standard therapy [25]. The primary efficacy end-point of a reduction in the total number of days of hospitalization for cardiovascular causes (or days deceased) within 60 days postrandomization was not reached $(12.5 \pm 14.0$ vs. $12.3 \pm 14.1$ days for placebo and milrinone, respectively, $P=0.71$ ) [25]. No significant differences were found between the placebo and the milrinone group for in-hospital mortality (2.3 vs. 3.8\%, $P=0.19$ ), 60 -day mortality ( 8.9 vs. $10.3 \%, P=0.41$ ), or combined 60-day death or readmission rates (35.3 vs. $35.0 \%, P=0.92$ ). Discontinuation rate of intravenous infusion was higher in patients randomized to milrinone compared to those on placebo (20.6 vs. $9.2 \%, P<0.001$ ), with higher rates of new-onset atrial fibrillation or flutter (4.6 vs. $1.5 \%, P=0.004)$, sustained hypotension (10.7 vs. $3.2 \%, P<0.001)$ and ventricular arrhythmias $(3.4$ vs. $1.5 \%, P=0.06$ ) [25]. A post hoc analysis of the OPTIMIZE-CHF has suggested that the increase in mortality associated with milrinone administration was more pronounced in patients with coronary artery disease with the composite end-point of death and rehospitalization occurring in 36 versus $42 \%$ of the ischemic patients treated with placebo and milrinone, respectively, and no significant differences between the two treatments among the nonischemic patients $(P=0.01$ for interaction $)$ [26].

\section{Advanced chronic HF}

The effects of inotropic agents in these patients have been investigated in several randomized controlled studies, including some large-scale trials. The first suggestion of an untoward effect of traditional inotropic agents on outcomes came from an analysis of 471 patients enrolled in the Flolan International Randomized Survival Trial FIRST trial [27]. Intravenous continuous dobutamine infusion (mean dose $9 \mu \mathrm{g} / \mathrm{kg} / \mathrm{min}$, range 5-12 $\mu \mathrm{g} / \mathrm{kg} / \mathrm{min}$, median duration of infusion, 14 days) was associated with an increase in the incidence of the primary composite endpoint of the study and of mortality alone ( 70.5 vs. $37.1 \%$; $P=0.0001)$, and it was the strongest independent predictor of mortality (HR 2.189, $P=0.0001$ ). Patients receiving dobutamine infusions had more severe $\mathrm{HF}$ as shown by the higher proportion of subjects in class IV (89 vs. $53 \%$ in class IV) and the lower systolic blood pressure $(100.5$ vs. $108.0 \mathrm{mmHg})$. However, the association between dobutamine infusion and poorer outcomes was maintained after adjustment for baseline variables [27].

The Dobutamina nell'Insufficienza Cardiaca Estrema (DICE) trial randomized 38 NYHA class III/IV patients with severe hemodynamic impairment to a 48 hours/week, 6 months, infusion of low-dose dobutamine $(2.5 \mu \mathrm{g} / \mathrm{kg} /$ $\mathrm{min}$ ) or placebo [28]. Intermittent dobutamine infusion was well tolerated and was associated with hemodynamic improvement and a trend toward lower hospitalization rates. However, 5 of 19 patients died in the dobutamine group versus 3 of 19 patients in the control group with also a tendency to a shorter time to death (93 vs. 114 days) [28].

Long-term treatment with oral PDE3-Is in patients with ACHF has been studied in several randomized controlled trials. Oral milrinone increased morbidity and mortality in 1,088 patients with chronic HF when compared to placebo in the pivotal Prospective Randomized Milrinone Survival Evaluation (PROMISE) trial [29]. The greatest increase in all-cause mortality was seen in the sickest patients with a $53 \%$ increase in risk with milrinone versus placebo $(P=$ 0.006 ) in NYHA class IV subjects when compared to a $28 \%$ increase in risk in the overall population $(P=0.038)$ [29].

The Vesnarinone Trial enrolled 3,833 patients (approximately $14 \%$ in NYHA class IV) randomized $1: 1: 1$ to placebo, vesnarinone $30 \mathrm{mg}$ and vesnarinone $60 \mathrm{mg}$. Quality of life significantly improved in the 60-mg vesnarinone group when compared to placebo at 8 and 16 weeks $(P<0.001$ and $P=0.003$, respectively). In contrast, over a mean follow-up of 286 days, there was a dose-dependent increase in all-cause mortality: $18.9 \%$ in the placebo group versus 21.0 and $22.9 \%$ in the $30-\mathrm{mg}$ and the $60-\mathrm{mg}$ vesnarinone group, respectively. High-dose vesnarinone was associated with a higher risk of sudden death (12.3 vs. $9.1 \%$ in the placebo group, OR, 1.35, 95\% CI: 1.08-1.69). Mortality data as well as changes in quality of life were similar in the placebo group and in the 30-mg vesnarinone group [29].

The Pimobendan In Congestive Heart Failure (PICO) trial randomized 317 patients with stable symptomatic 
NYHA class II-III HF to placebo or pimobendan 2.5 or $5 \mathrm{mg}$ daily [30]. The primary outcome was exercise time (by bicycle ergometry) at 4, 12 and 24 weeks after the start of the study. Both pimobendan dosages improved exercise duration by $6 \%$ ( $P=0.03$ and 0.05 , respectively) after 24 weeks with no change in peak oxygen consumption and on quality of life, but there was also a trend to an increased risk of death (OR 1.8, 95\%CIs: 0.9-3.5 for pimobendan versus placebo) [31]. Long-term administration of enoximone at high doses ( $\geq 100 \mathrm{mg}$ tid) has also been associated with increased mortality [32].

The consistent results of randomized clinical trials have led to slowing in the development of inotropic agents for the chronic treatment of severe HF. However, some issues remain. First, a few patients may not be stabilized by standard treatment and may still need chronic inotropic support as bridging to heart transplantation or a ventricular assist device implantation and/or as symptomatic palliation for end-stage disease. Such an indication is also accepted in the guidelines [11-13] and is often accomplished through intermittent intravenous therapy with either dobutamine or milrinone [33].

Second, concomitant administration of beta-blocking agents, ICDs implantation, as well as the administration of lower doses might allow better tolerance and avoid the effects on mortality and disease progression of even traditional inotropic agents [32, 34]. This hypothesis has been tested in placebo-controlled trials of low-dose (i.e. 25-50 mg tid) oral enoximone administration to patients on intermittent inotropic therapy [35] and with advanced chronic HF on optimal oral medical treatment in the Studies of Oral Enoximone Therapy in Advanced Heart Failure (ESSENTIAL) trials, respectively [36]. Despite some favorable trends, these trials failed to show beneficial effects with respect to freedom from death or reinitiation of intravenous therapy, in the first study [35], and with respect to time to death or rehospitalization in the second, larger (1,854 patients), trial [36]. It must be noted, however, that, for the first time, these trials showed a lack of untoward effects on mortality as well as favorable trends in some end-points such as a trend to lower mortality and reinstitution of intravenous therapy over the 182-day study period (HR, 0.76, 95\%CIs: 0.55-1.04) in the trial in patients on inotropic support [35], and a tendency to better results in the 6-min walk test in the patients with more severe HF enrolled in ESSENTIAL [36].

\section{Mechanisms of the untoward effects on outcomes}

The mechanisms of the untoward effects of traditional inotropic agents on survival are multiple but seem mainly related to tachyarrhythmias and myocardial ischemia and
Table 2 Limitations of inotropic agents
Tachyarrhythmias
Increased ventricular arrhythmias
Increased ventricular rate in atrial fibrillation
Myocardial ischemia
Hypotension-coronary hypoperfusion
Increased heart rate and myocardial contractility-increased myocardial oxygen consumption
Direct myocyte toxicity—intracellular calcium overload

damage (Table 2). Atrial and ventricular tachyarrhythmias are often present in patients with AHFS and ACHF. Though they may not have an independent prognostic role in patients with chronic HF they may contribute to the poor survival of patients in unstable conditions through further worsening of hemodynamics and increased myocardial oxygen consumption. Traditional inotropic agents, especially dobutamine and PDE3-Is, have concomitant vasodilating effects. Though this vasodilation may be beneficial in patients with normal to high blood pressure, through the effects of afterload reduction, this may have deleterious consequences when these agent are given to patients with low to normal blood pressure. Excessive peripheral vasodilation may, in fact, cause coronary hypoperfusion and further myocardial damage, a mechanism likely contributing to the poor prognosis of patients with AHFS [6, 37].

In the patients with AHFS, the administration of inotropic agents may also favor myocardial ischemia and damage through increased myocardial oxygen consumption caused by tachycardia and increased myocardial contractility. Traditional inotropes also decrease myocardial efficiency thus increasing oxygen expenditure for any amount of myocardial work. As shown in an experimental model of myocardial infarction, inotropic stimulation with dobutamine may cause necrosis in areas of myocardial hibernation with further loss of vital myocardium [38]. The negative interaction between inotropic agents and coronary artery disease is also demonstrated by the increase in mortality in patients with ischemic cardiomyopathy receiving milrinone in the OPTIME-CHF trial [26].

All the mechanisms related to the untoward effects of inotropic agents on outcomes seem therefore to be related to cAMP stimulation with a consequent rise in intracellular calcium concentrations in the cardiomyocytes and to peripheral vasodilation. Unfortunately, this effect is the same mechanism by which these agents increase inotropy. Consequently, with most current therapies, the mechanism of the beneficial hemodynamic effects is the same cause of the adverse effects. Inotropic agents acting independently from these pathways should not necessarily have untoward effects on survival and, perhaps, we have a good starting example with digitalis therapy. 


\section{The case of digoxin}

The evidence on the beneficial properties of digoxin in the setting of HF has been gathered from over 200 years of clinical and experimental research [39]. Digoxin acts through inhibition of the sarcolemmal Na-K ATPase pump thus leading to increased intracellular sodium that is then exchanged with calcium. The increase in intracellular calcium causes the inotropic effect of the drug.

The beneficial hemodynamic effects of digoxin are attained in the absence of any hypotension or tachycardia and with associated favorable effects on neurohormones including a decrease in the sympathetic drive and reninangiotensin-aldosterone activation and an increase in vagal stimulation [39]. Despite these favorable results, few studies have assessed the effects of digoxin in patients with acute HF [40].

Conversely, digoxin use is rather common in patients with chronic HF (approximately $50-65 \%$ of patients overall, range 55-91\%) [39]. The landmark Digitalis Investigators Group (DIG) trial assessed the effects of digoxin on mortality in a total of 7,788 patients with chronic stable HF ( $\sim 85 \%$ NYHA class II-III) randomized to placebo or digoxin with treatment targeting to serum digoxin concentrations $0.8-2.5 \mathrm{ng} / \mathrm{ml}$ [41]. The study included 6,800 HF patients with EF $\leq 45 \%$ (DIG-Main) and 988 patients with EF $>45 \%$ (DIG-Ancillary). The median daily dose of digoxin was $0.25 \mathrm{mg}$. Although digoxin did not reduce the primary end-point of all-cause mortality during 37 months of follow-up, it did significantly reduce HF-related deaths or rehospitalization [41].

Further data analyses showed the pivotal role of the serum digoxin concentrations achieved during treatment. This issue was first addressed in a post hoc analysis by Gheorghiade et al. This study showed that while the effects of digoxin on LV function are dose dependent, increasing serum digoxin concentrations have no relation with changes in exercise tolerance and neurohormonal parameters [42]. In a post hoc analysis of the DIG trial restricted to male patients with $\mathrm{LV} \mathrm{EF} \leq 45 \%(n=3,782)$, there was a positive correlation between increased mortality and serum digoxin concentrations [43]. Patients with the lowest concentrations $(0.5-0.8 \mathrm{ng} / \mathrm{ml})$ showed the lowest mortality rate with digoxin compared to placebo $(6.3 \%$ decrease, 95\% CI: $2.1-10.5 \%$ ), with no effect at concentrations of $0.9-1.1 \mathrm{ng} / \mathrm{ml}$ and a higher mortality with digoxin in patients with digoxin concentrations $>1.2 \mathrm{ng} / \mathrm{ml}(11.8 \%$ increase, 95\% CI: 5.7-18.0\%). Lower serum levels were later reported to be consistently associated with reduced mortality and hospitalization in all the patients enrolled in the DIG trial regardless of EF during 40-month median follow-up [43]. Another independent analysis confirmed the "bidirectional relation" between serum digoxin concentrations and mortality with reduced mortality at values of serum digoxin concentrations of $0.5-0.9 \mu \mathrm{g} / \mathrm{kg} /$ $\min$ [44].

It is also possible that follow-up duration, actually longer than in most of other controlled trials in HF, influenced the results. A recent post hoc analysis has shown that digoxin reduces 1-year all-cause mortality (HR for digoxin $0.87,95 \%$ CI: $0.76-0.995, P=0.043$ ), cardiovascular mortality (HR, $0.87,95 \%$ CI: $0.75-1.01, P=0.072$ ), HF mortality (HR, $0.66,95 \%$ CI: $0.52-0.85, P=0.001$ ) and all-cause hospitalization (HR, $0.89,95 \%$ CI: $0.83-0.96$, $P=0.002)$ in patients from the DIG trial irrespective of digoxin concentration [45].

Thus, digoxin administration targeted to low serum levels may be associated with hemodynamic and clinical improvements, reduced morbidity and possibly increased survival. Implementation of this agent is, however, limited by its narrow risk to benefit ratio. Currently, recommended target therapeutic ranges are lower than in the past and than those aimed to in the DIG trial, so that potential side-effects related to digoxin toxicity are supposedly less frequent than previously observed. Lastly, digoxin, the oldest drug currently used for the treatment of $\mathrm{HF}$, may be the agent to open new tracks for the research on inotropic agents. We will briefly summarize herewith data regarding more recent inotropic agents with novel mechanisms of action.

\section{New mechanisms, new inotropic agents}

A detailed description of these agents is beyond the aims of this review. However, we will summarize some of the main results and perspectives with respect to some of them.

\section{Levosimendan}

Levosimendan is a calcium sensitizing agent with two complimentary mechanisms of action, enhanced cardiac troponin $\mathrm{C}$ sensitivity to intracellular calcium and peripheral vasodilation through opening of smooth muscle ATPdependent potassium channels, as well as some potential PDE3-I activity. These mechanisms mediate its inotropic and vasodilating effects, respectively. A detailed description of the mechanisms of action and clinical effects of levosimendan is beyond the aims of this review and thorough reviews are available $[46,47]$.

The recent Randomized Multicenter Evaluation of Intravenous Levosimendan Efficacy Versus Placebo in the Short-Term Treatment of Decompensated Heart Failure (REVIVE) trial, consisting of 2 consecutive phases, REVIVE-1 $(n=100)$ and $-2(n=600)$, investigated the effect on levosimendan versus placebo on primary combined end-points. Particularly, the primary end-point of 
REVIVE-II was a composite based on patients' self-rating as moderately or markedly improved at $6 \mathrm{~h}, 24 \mathrm{~h}$ and 5 days in the absence of any criteria for worsening [48]. In the REVIVE-2, despite a significant improvement of the primary end-point in patients randomized to levosimendan (overall $P=0.015$ ), active drug treatment was associated with higher rates of adverse effects, including hypotension (49 vs. $36 \%$ on placebo), ventricular tachycardia (24 vs. $17 \%$ on placebo) and atrial fibrillation (4 vs. 1\%). Mortality at 90 days was of $15 \%$ in the levosimendan group versus $12 \%$ with placebo $(P=0.210)[48]$.

All-cause mortality was the primary end-point of the Survival of Patients with Acute Heart Failure in Need of Intravenous Inotropic Support (SURVIVE) study in which levosimendan was compared to dobutamine [49]. In SURVIVE, 1,327 patients hospitalized for HF were randomized to levosimendan $(12 \mu \mathrm{g} / \mathrm{kg}$ loading dose followed by $1-\mathrm{h}$ at $0.1 \mu \mathrm{g} / \mathrm{kg} / \mathrm{min}$ up-titrated to $0.2 \mu \mathrm{g} / \mathrm{kg} / \mathrm{min}$ for the following $23 \mathrm{~h}$ ) or dobutamine (starting dose $5 \mu \mathrm{g} / \mathrm{kg} / \mathrm{min}$ ) [49]. Mortality at 180 days was similar in the two treatment groups (26 vs. $28 \%$, HR for levosimendan $0.91,95 \% \mathrm{CI}$ : $0.74-1.13, P=0.40$ ). The lack of any survival benefit with levosimendan, compared with dobutamine, has been ascribed to the associated vasodilatory action of levosimendan, when administered at the doses used in this trial [49]. Other contributing factors may have been tachycardia with levosimendan and unsatisfactory patients selection with inclusion of patients with new-onset AHF (mortality was of $26 \%$ in the levosimendan versus $17 \%$ in the dobutamine group, HR, $1.61,95 \% \mathrm{CI}$ : $0.80-3.25, P=0.05$ for interaction with previous $\mathrm{HF}$ ) [49].

Despite interesting new mechanisms of action and favorable results in preliminary trials, more recent studies have thus failed to yield conclusive results regarding the risk to benefit ratio of levosimendan in patients with AHFS.

\section{Istaroxime}

Istaroxime is a novel agent, with both inotropic and lusitropic effects. It inhibits the sarcolemmal $\mathrm{Na}-\mathrm{K}$ ATPase, thus increasing cytosolic calcium and stimulating sarcoplasmic reticulum calcium ATPase isoform-2 (SERCA-2). This last action enhances calcium reuptake by the sarcoplasmic reticulum, favoring myocardial relaxation. Greater sarcoplasmic reticulum calcium reuptake during diastole also leads to greater calcium available for release at the next systole and, thus, has also a positive inotropic effect [50, 51].

In an experimental canine model of ischemic advanced chronic HF, continuous infusion of escalating doses of istaroxime $(0.5,1.0,2.0,3.0$, and $5.0 \mu \mathrm{g} / \mathrm{kg} / \mathrm{min})$ increased LV $\mathrm{EF}$ in a dose-dependent fashion from $0.25 \pm 0.01 \%$ to $0.42 \pm 0.02 \%$ at the highest dose $(P<0.05)$, with no increase in myocardial oxygen consumption [50]. Diastolic parameters were also improved, and no arrhythmias were detected. A recently published study assessed the hemodynamic effects of istaroxime in 120 patients admitted for AHF with left ventricular ejection fraction $\leq 35 \%$ (mean $27 \pm$ $7 \%)$ and low systolic blood pressure $(116 \pm 3 \mathrm{mmHg})$ randomized $3: 1$ to a $6 \mathrm{~h}$ continuous infusion of 3 different doses of istaroxime $(0.5,1.0$ and $1.5 \mu \mathrm{g} / \mathrm{kg} / \mathrm{min})$ or placebo. [52]. Istaroxime infusion was associated with a reduction in pulmonary capillary wedge pressure, the primary end-point of the study ( $P<0.05$ for all 3 doses vs. placebo) and an increase in stroke work index (at $1.5 \mu \mathrm{g} / \mathrm{kg} / \mathrm{min}$ ). Unlike traditional intravenous inotropic agents, istaroxime was associated with a dose-dependent reduction in heart rate and an increase in systolic BP [52]. Hemodynamic and echocardiographic analyses of these data have confirmed findings from the previous study, showing a decrease in left ventricular volumes and an improvement in left ventricular ejection fraction with istaroxime administration and has shown its lusitropic effects with an increase in the lateral mitral annulus early diastolic velocity $\left(\mathrm{E}^{\prime}\right)$, a prolongation of the E-wave deceleration half-time and a decrease in the E/A ratio of transmitral flow velocity [53].

Thus, istaroxime has a unique hemodynamic profile with an improvement in left ventricular diastolic function and a reduction in ventricular filling pressure attended by slowing of heart rate and no change or an increase in systolic blood pressure.

\section{Cardiac myosin activators}

These agents directly target myocardial myosin ATPase, increasing the rate of effective myosin cross-bridge formation, and hence the duration and amount of myocyte contraction with increased myocyte energy utilization, and no effect on intracellular calcium or cAMP [4, 54]. Active research in the recent past has led to the development of the selective cardiac myosin activator CK-1827452, now known as omecamtiv mecarbil, the first agent to be tested in humans [54]. In a pivotal phase I trial by Teerlink et al. on 34 healthy volunteers, omecamtiv mecarbil, at the dose of $0.5 \mathrm{mg} / \mathrm{kg} /$ min given as a 6 -h continuous infusion, induced a $6.8 \%$ and a 9.2\% absolute increase in EF and in fractional shortening, respectively $(P<0.0001$ for both) [54]. Systolic ejection time was prolonged by a mean $84 \mathrm{~ms}(P<0.0001)$. These findings, as well as those observed in experimental models, are consistent with a unique positive inotropic effect elicited through direct increase in systolic ejection time rather than through increase in contraction velocity. The first Phase II trial of omecamtiv mecarbil was a multi-center, doubleblind, randomized, placebo-controlled study in a total of 45 stable heart failure patients treated with an ACE inhibitor (or ARB) and a beta-blocker, \pm diuretics, exposed to a total of 151 dosing periods divided among 5 cohorts. In Cohorts 1-4, 
patients each received four treatments: three escalating doses of omecamtiv mecarbil and one placebo treatment that was randomized into the dosing sequence to maintain blinding. Each of the four treatments was at least 1 week apart. In Cohort 5, patients received two 72-h treatments, omecamtiv mecarbil and placebo in a double-blind crossover fashion. This study confirmed the findings of the Phase I study, with concentration-dependent increases in the systolic ejection time accompanied by improvements in fractional shortening, stroke volume, ejection fraction with associated decreases in heart rate. No difference in these effects has been found between patients with ischemic and nonischemic cardiomyopathy. To date, this agent has been safe and well tolerated. Additional Phase II trials are currently underway in patients with HF [54] and ischemic heart disease. Cardiac myosin activators may be expected to play an active role in the quest for the ideal, safe and effective inotropic agent, and the availability of a highly bioavailable oral formulation suggests that these benefits may be extended to therapy of chronic heart failure.

\section{Metabolic modulators}

Cardiac performance may also be enhanced by modifying substrate utilization from free fatty acids to more efficient fuels like glucose and lactate. This may result in a net $10-15 \%$ saving in oxygen consumption [4, 5]. Metabolic modulators have been extensively studied and are currently used in patients with ischemic heart disease, specifically stable angina. Among others, ranolazine, perhexiline and trimetazidine have also been investigated in experimental and clinical HF showing beneficial effects [4]. Ranolazine has shown favorable hemodynamic effects both acutely [55] and chronically, on LV remodeling. In an experimental model of microembolization-induced $\mathrm{HF}$ it was associated with prevention of the increase in end-diastolic and end-systolic left ventricular volumes and an increase in LV ejection fraction $[56,57]$.

Trimetazidine and perhexiline administration have been associated with symptomatic improvements and beneficial effects on quality of life, exercise tolerance and left ventricular systolic function [58, 59].

\section{SERCA 2A activators}

Reuptake of calcium into the sarcoplasmic reticulum occurs via SERCA2a, which is downregulated in HF. This accounts for the increase in free intracytoplasmatic calcium in the cardiomyocytes, a major responsible for impaired cardiac function and tachyarrhythmias. Hence, SERCA2a is now a major target for treatment of both HF with preserved LV ejection fraction and HF with low LV ejection fraction. One biological agent under development in this category is MYDICAR, an adeno-associated viral-vector carrying the gene for SERCA2a. The drug is being studied now and is administered by intracoronary injections to patients with end-stage heart failure (Calcium Up-Regulation by Percutaneous Administration of Gene Therapy In Cardiac Disease trial [CUPID]). The results of this phase 2 double-blind study will be known in 2010 [60, 61].

In addition to gene therapy, a class of novel small molecules, acting as allosteric compounds, is under development and in preclinical models have been found to modulate SERCA2a activity and increase $V_{\max }$ and contractility without increasing energy utilization, making them important candidates as new IV inotropic drugs. Clinical studies are expected to start in 2010.

\section{Conclusions}

Many studies have consistently shown that current inotropic therapies are associated with increased mortality in patients with both acute and chronic HF. Tachyarrhythmias and myocardial damage, exacerbated by hypotension and increased myocardial oxygen consumption, are the most likely mechanisms of the untoward effects of these agents. According to this hypothesis, the unfavorable effects on outcomes are mechanism-dependent and not intrinsic to changes in myocardial contractility. Recently published guidelines have needed to account for the mechanism of action and the benefit to risk profiles of these agents. Dobutamine, milrinone (and other PDE3-Is) and levosimendan are all potent vasodilators, and consequently, their guideline recommended use in patients with systolic blood pressures less than $90 \mathrm{mmHg}$ presents significant clinical challenges. All of these agents have been associated with significant and life-threatening adverse effects, such that their recommended use is limited only to those patients at high risk for poor outcomes, and it is clearly difficult to improve survival in them.

However, it is important to recall that over half of the greater than 1.1 million hospitalizations for heart failure in the US alone are in patients with reduced systolic function. Thus, there is still a potential indication to inotropic therapy. Digoxin, the oldest inotropic agent used in clinical practice, has not been associated with worse outcomes in the controlled trials. More studies regarding its efficacy and tolerability in the current era of HF treatment are warranted. New, potentially safer, positive inotropic agents, such as istaroxime and omecamtiv mecarbil, may increase dramatically the number of patients who may benefit from this type of therapy. New agents with more favorable effects on myocardial perfusion and cardiac efficiency are likely going to open new pathways to improve quality of life and outcomes of patients with advanced HF. 
Open Access This article is distributed under the terms of the Creative Commons Attribution Noncommercial License which permits any noncommercial use, distribution, and reproduction in any medium, provided the original author(s) and source are credited.

\section{References}

1. Stevenson LW (2003) Clinical use of inotropic therapy for heart failure: looking backward or forward? Part I: inotropic infusions during hospitalization. Circulation 108:367-372

2. Stevenson LW (2003) Clinical use of inotropic therapy for heart failure: looking backward or forward? Part II: chronic inotropic therapy. Circulation 108:492-497

3. Teerlink JR (2005) Overview of randomized clinical trials in acute heart failure syndromes. Am J Cardiol 96:59G-67G

4. deGoma EM, Vagelos RH, Fowler MB, Ashley EA (2006) Emerging therapies for the management of decompensated heart failure: from bench to bedside. J Am Coll Cardiol 48:2397-2409

5. De Luca L, Mebazaa A, Filippatos G, Parissis JT, Böhm M, Voors AA, Nieminen M, Zannad F, Rhodes A, El-Banayosy A, Dickstein K, Gheorghiade M (2008) Overview of emerging pharmacologic agents for acute heart failure syndromes. Eur J Heart Fail 10:201-213

6. Gheorghiade M, Pang PS (2009) Acute heart failure syndromes. J Am Coll Cardiol 53:557-573

7. Gheorghiade M, Abraham WT, Albert NM, Greenberg BH, O'Connor CM, She L, Stough WG, Yancy CW, Young JB, Fonarow GC, OPTIMIZE-HF Investigators and Coordinators (2006) Systolic blood pressure at admission, clinical characteristics, and outcomes in patients hospitalized with acute heart failure. JAMA 296:2217-2226

8. Nieminen MS, Brutsaert D, Dickstein K, Drexler H, Follath F, Harjola VP, Hochadel M, Komajda M, Lassus J, Lopez-Sendon JL, Ponikowski P, Tavazzi L, EuroHeart Survey Investigators, Heart Failure Association, European Society of Cardiology (2006) EuroHeart Failure Survey II (EHFS II): a survey on hospitalized acute heart failure patients: description of population. Eur Heart J 27:2725-2736

9. Tavazzi L, Maggioni AP, Lucci D, Cacciatore G, Ansalone G, Oliva F, Porcu M, Italian survey on Acute Heart Failure Investigators (2006) Nationwide survey on acute heart failure in cardiology ward services in Italy. Eur Heart J 27:1207-1215

10. Nieminen MS, Böhm M, Cowie MR, Drexler H, Filippatos GS, Jondeau G, Hasin Y, Lopez-Sendon J, Mebazaa A, Metra M, Rhodes A, Swedberg K, Priori SG, Garcia MA, Blanc JJ, Budaj A, Cowie MR, Dean V, Deckers J, Burgos EF, Lekakis J, Lindahl B, Mazzotta G, Morais J, Oto A, Smiseth OA, Garcia MA, Dickstein K, Albuquerque A, Conthe P, Crespo-Leiro M, Ferrari R, Follath F, Gavazzi A, Janssens U, Komajda M, Morais J, Moreno R, Singer M, Singh S, Tendera M, Thygesen K, ESC Committe for Practice Guideline (CPG) (2005) Executive summary of the guidelines on the diagnosis and treatment of acute heart failure: the task force on acute heart failure of the European Society of Cardiology. Eur Heart J 26:384-416

11. Heart Failure Society of America (2006) Executive summary: HFSA 2006 comprehensive heart failure practice guideline. J Card Fail 12:10-38

12. European Society of Cardiology, Heart Failure Association of the ESC (HFA), European Society of Intensive Care Medicine (ESICM), Dickstein K, Cohen-Solal A, Filippatos G, McMurray JJ, Ponikowski P, Poole-Wilson PA, Strömberg A, van Veldhuisen DJ, Atar D, Hoes AW, Keren A, Mebazaa A, Nieminen M, Priori SG, Swedberg K, Vahanian A, Camm J, De Caterina R, Dean V, Dickstein K, Filippatos G, Funck-Brentano C,
Hellemans I, Kristensen SD, McGregor K, Sechtem U, Silber S, Tendera M, Widimsky P, Zamorano JL, Tendera M, Auricchio A, Bax J, Böhm M, Corrà U, Della Bella P, Elliott PM, Follath F, Gheorghiade M, Hasin Y, Hernborg A, Jaarsma T, Komajda M, Kornowski R, Piepoli M, Prendergast B, Tavazzi L, Vachiery JL, Verheugt FW, Zamorano JL, Zannad F (2008) ESC guidelines for the diagnosis and treatment of acute and chronic heart failure 2008: the task force for the diagnosis and treatment of acute and chronic heart failure 2008 of the European Society of Cardiology. Developed in collaboration with the Heart Failure Association of the ESC (HFA) and endorsed by the European Society of Intensive Care Medicine (ESICM). Eur J Heart Fail 10:933-989

13. Jessup M, Abraham WT, Casey DE, Feldman AM, Francis GS, Ganiats TG, Konstam MA, Mancini DM, Rahko PS, Silver MA, Stevenson LW, Yancy CW (2009) 2009 focused update: ACCF/ AHA Guidelines for the diagnosis and management of heart failure in adults: a report of the American College of Cardiology Foundation/American Heart Association task force on practice guidelines: developed in collaboration with the International Society for Heart and Lung Transplantation. Circulation 119:1977-2016

14. Yancy CW, Lopatin M, Stevenson LW, De Marco T, Fonarow GC, ADHERE Scientific Advisory Committee and Investigators (2006) Clinical presentation, management, and in-hospital outcomes of patients admitted with acute decompensated heart failure with preserved systolic function: a report from the Acute Decompensated Heart Failure National Registry (ADHERE) Database. J Am Coll Cardiol 47:76-84

15. Adams KF Jr, Fonarow GC, Emerman CL, LeJemtel TH, Costanzo MR, Abraham WT, Berkowitz RL, Galvao M, Horton DP, ADHERE Scientific Advisory Committee and Investigators (2005) Characteristics and outcomes of patients hospitalized for heart failure in the United States: rationale, design, and preliminary observations from the first 100,000 cases in the Acute Decompensated Heart Failure National Registry (ADHERE). Am Heart J 149:209-216

16. Nohria A, Lewis E, Stevenson LW (2002) Medical management of advanced heart failure. JAMA 287:628-640

17. Nohria A, Tsang SW, Fang JC, Lewis EF, Jarcho JA, Mudge GH, Stevenson LW (2003) Clinical assessment identifies hemodynamic profiles that predict outcomes in patients admitted with heart failure. J Am Coll Cardiol 41:1797-1804

18. Metra M, Ponikowski P, Dickstein K, McMurray JJ, Gavazzi A, Bergh CH, Fraser AG, Jaarsma T, Pitsis A, Mohacsi P, Böhm M, Anker S, Dargie H, Brutsaert D, Komajda M, Heart Failure Association of the European Society of Cardiology (2007) Advanced chronic heart failure: a position statement from the study group on Advanced Heart Failure of the Heart Failure Association of the European Society of Cardiology. Eur J Heart Fail 9:684-694

19. Jaarsma T, Beattie JM, Ryder M, Rutten FH, McDonagh T, Mohacsi P, Murray SA, Grodzicki T, Bergh I, Metra M, Ekman I, Angermann C, Leventhal M, Pitsis A, Anker SD, Gavazzi A, Ponikowski P, Dickstein K, Delacretaz E, Blue L, Strasser F, McMurray J, Advanced Heart Failure Study Group of the HFA of the ESC (2009) Palliative care in heart failure: a position statement from the palliative care workshop of the Heart Failure Association of the European Society of Cardiology. Eur J Heart Fail 11:433-443

20. Stevenson LW, Pagani FD, Young JB, Jessup M, Miller L, Kormos RL, Naftel DC, Ulisney K, Desvigne-Nickens P, Kirklin JK (2009) INTERMACS profiles of advanced heart failure: the current picture. J Heart Lung Transplant 28:535-541

21. Gheorghiade M, Adams KF, Cleland JG, Cotter G, Felker GM, Filippatos GS, Fonarow GC, Greenberg BH, Hernandez AF, Khan S, Komajda M, Konstam MA, Liu PP, Maggioni AP, 
Massie BM, McMurray JJ, Mehra M, Metra M, O'Connell J, O'Connor CM, Pang PS, Piña IL, Sabbah HN, Teerlink JR, Udelson JE, Yancy CW, Zannad F, Stockbridge N, Acute Heart Failure Syndromes International Working Group (2009) Phase III clinical trial end points in acute heart failure syndromes: a virtual roundtable with the Acute Heart Failure Syndromes International Working Group. Am Heart J 157:957-970

22. Abraham WT, Adams KF, Fonarow GC, Costanzo MR, Berkowitz RL, LeJemtel TH, Cheng ML, Wynne J, ADHERE Scientific Advisory Committee and Investigators, ADHERE Study Group (2005) In-hospital mortality in patients with acute decompensated heart failure requiring intravenous vasoactive medications: an analysis from the Acute Decompensated Heart Failure National Registry (ADHERE). J Am Coll Cardiol 46:57-64

23.. Elkayam U, Tasissa G, Binanay C, Stevenson LW, Gheorghiade M, Warnica JW, Young JB, Rayburn BK, Rogers JG, DeMarco T, Leier CV (2007) Use and impact of inotropes and vasodilator therapy in hospitalized patients with severe heart failure. Am Heart J 153:98-104

24. Thackray S, Easthaugh J, Freemantle N, Cleland JG (2002) The effectiveness and relative effectiveness of intravenous inotropic drugs acting through the adrenergic pathway in patients with heart failure-a meta-regression analysis. Eur J Heart Fail 4: $515-529$

25. Cuffe MS, Califf RM, Adams KF Jr, Benza R, Bourge R, Colucci WS, Massie BM, O'Connor CM, Pina I, Quigg R, Silver MA, Gheorghiade M, Outcomes of a Prospective Trial of Intravenous Milrinone for Exacerbations of Chronic Heart Failure (OPTIMECHF) Investigators (2002) Short-term intravenous milrinone for acute exacerbation of chronic heart failure: a randomized controlled trial. JAMA 287:1541-1547

26. Felker GM, Benza RL, Chandler AB, Leimberger JD, Cuffe MS, Califf RM, Gheorghiade M, O'Connor CM, OPTIME-CHF Investigators (2003) Heart failure etiology and response to milrinone in decompensated heart failure: results from the OPTIMECHF study. J Am Coll Cardiol 41:997-1003

27. O'Connor CM, Gattis WA, Uretsky BF, Adams KF Jr, McNulty SE, Grossman SH, McKenna WJ, Zannad F, Swedberg K, Gheorghiade M, Califf RM (1999) Continuous intravenous dobutamine is associated with an increased risk of death in patients with advanced heart failure: insights from the Flolan International Randomized Survival Trial (FIRST). Am Heart J 138:78-86

28. Oliva F, Latini R, Politi A, Staszewsky L, Maggioni AP, Nicolis E, Mauri F (1999) Intermittent 6-month low-dose dobutamine infusion in severe heart failure: DICE multicenter trial. Am Heart J 138:247-253

29. Packer M, Carver JR, Rodeheffer RJ, Ivanhoe RJ, DiBianco R, Zeldis SM, Hendrix GH, Bommer WJ, Elkayam U, Kukin ML et al (1991) Effect of oral milrinone on mortality in severe chronic heart failure. The PROMISE Study Research Group. N Engl J Med 325:1468-1475

30. Cohn JN, Goldstein SO, Greenberg BH, Lorell BH, Bourge RC, Jaski BE, Gottlieb SO, McGrew F III, DeMets DL, White BG (1998) A dose-dependent increase in mortality with vesnarinone among patients with severe heart failure. Vesnarinone Trial Investigators. N Engl J Med 339:1810-1816

31. Lubsen J, Just H, Hjalmarsson AC, La Framboise D, Remme WJ, Heinrich-Nols J, Dumont JM, Seed P (1996) Effect of pimobendan on exercise capacity in patients with heart failure: main results from the Pimobendan in Congestive Heart Failure (PICO) trial. Heart 76(3):223-231

32. Lowes BD, Shakar SF, Metra M, Feldman AM, Eichhorn E, Freytag JW, Gerber MJ, Liard JF, Hartman C, Gorczynski R, Evans G, Linseman JV, Stewart J, Robertson AD, Roecker EB, Demets DL, Bristow MR (2005) Rationale and design of the enoximone clinical trials program. J Card Fail 11:659-669
33. Gorodeski EZ, Chu EC, Reese JR, Shishehbor MH, Hsich E, Starling RC (2009) Prognosis on chronic dobutamine or milrinone infusions for stage D heart failure. Circ Heart Fail 2: 320-324

34. Metra M, Nodari S, D'Aloia A, Muneretto C, Robertson AD, Bristow MR, Dei Cas L (2002) Beta-blocker therapy influences the hemodynamic response to inotropic agents in patients with heart failure: a randomized comparison of dobutamine and enoximone before and after chronic treatment with metoprolol or carvedilol. J Am Coll Cardiol 40:1248-1258

35. Feldman AM, Oren RM, Abraham WT, Boehmer JP, Carson PE, Eichhorn E, Gilbert EM, Kao A, Leier CV, Lowes BD, Mathier MA, McGrew FA, Metra M, Zisman LS, Shakar SF, Krueger SK, Robertson AD, White BG, Gerber MJ, Wold GE, Bristow MR, EMOTE Study Group (2007) Low-dose oral enoximone enhances the ability to wean patients with ultra-advanced heart failure from intravenous inotropic support: results of the oral enoximone in intravenous inotrope-dependent subjects trial. Am Heart J 154:861-869

36. Metra M, Eichhorn E, Abraham WT, Linseman J, Böhm M, Corbalan R, Demets D, De Marco T, Elkayam U, Gerber M, Komajda M, Liu P, Mareev V, Perrone SV, Poole-Wilson P, Roecker E, Stewart J, Swedberg K, Tendera M, Wiens B, Bristow MR; for the ESSENTIAL Investigators (2009) Effects of lowdose oral enoximone administration on mortality, morbidity, and exercise capacity in patients with advanced heart failure: the randomized, double-blind, placebo-controlled, parallel group ESSENTIAL trials. Eur Heart J. [Epub ahead of print] PubMed PMID: 19700774

37. Beohar N, Erdogan AK, Lee DC, Sabbah HN, Kern MJ, Teerlink J, Bonow RO, Gheorghiade M (2008) Acute heart failure syndromes and coronary perfusion. J Am Coll Cardiol 52:13-16

38. Schulz R, Rose J, Martin C, Brodde OE, Heusch G (1993) Development of short-term myocardial hibernation. Its limitation by the severity of ischemia and inotropic stimulation. Circulation 88:684-695

39. Gheorghiade M, van Veldhuisen DJ, Colucci WS (2006) Contemporary use of digoxin in the management of cardiovascular disorders. Circulation 113:2556-2564

40. Gheorghiade M, Hall V, Lakier JB, Goldstein S (1989) Comparative hemodynamic and neurohormonal effects of intravenous captopril and digoxin and their combinations in patients with severe heart failure. J Am Coll Cardiol 13:134-142

41. The Digitalis Investigation Group (1997) The effect of digoxin on mortality and morbidity in patients with heart failure. N Engl J Med 336:525-533

42. Gheorghiade M, Hall VB, Jacobsen G, Alam M, Rosman H, Goldstein S (1995) Effects of increasing maintenance dose of digoxin on left ventricular function and neurohormones in patients with chronic heart failure treated with diuretics and angiotensin-converting enzyme inhibitors. Circulation 92:18011807

43. Rathore SS, Curtis JP, Wang Y, Bristow MR, Krumholz HM (2003) Association of serum digoxin concentration and outcomes in patients with heart failure. JAMA 289:871-878

44. Ahmed A, Rich MW, Love TE, Lloyd-Jones DM, Aban IB, Colucci WS, Adams KF, Gheorghiade M (2006) Digoxin and reduction in mortality and hospitalization in heart failure: a comprehensive post hoc analysis of the DIG trial. Eur Heart $\mathbf{J}$ 27:178-186

45. Digitalis Investigation Group, Ahmed A, Waagstein F, Pitt B, White M, Zannad F, Young JB, Rahimtoola SH (2009) Effectiveness of digoxin in reducing one-year mortality in chronic heart failure in the Digitalis Investigation Group trial. Am J Cardiol 103:82-87 
46. De Luca L, Colucci WS, Nieminen MS, Massie BM, Gheorghiade $M$ (2006) Evidence-based use of levosimendan in different clinical settings. Eur Heart J 27:1908-1920

47. Parissis JT, Rafouli-Stergiou P, Paraskevaidis I, Mebazaa A (2008) Levosimendan: from basic science to clinical practice. Heart Fail Rev. [Epub ahead of print] PubMed PMID: 19101796

48. Cleland JG, Freemantle N, Coletta AP, Clark AL (2006) Clinical trials update from the American Heart Association: REPAIRAMI, ASTAMI, JELIS, MEGA, REVIVE-II, SURVIVE, and PROACTIVE. Eur J Heart Fail 8(1):105-110

49. Mebazaa A, Nieminen MS, Packer M, Cohen-Solal A, Kleber FX, Pocock SJ, Thakkar R, Padley RJ, Põder P, Kivikko M, SURVIVE Investigators (2007) Levosimendan vs dobutamine for patients with acute decompensated heart failure: the SURVIVE randomized trial. JAMA 297:1883-1891

50. Sabbah HN, Imai M, Cowart D, Amato A, Carminati P, Gheorghiade M (2007) Hemodynamic properties of a new-generation positive luso-inotropic agent for the acute treatment of advanced heart failure. Am J Cardiol 99:41A-46A

51. Khan H, Metra M, Blair JE, Vogel M, Harinstein ME, Filippatos GS, Sabbah HN, Porchet H, Valentini G, Gheorghiade M (2009) Istaroxime, a first in class new chemical entity exhibiting SERCA-2 activation and Na-K-ATPase inhibition: a new promising treatment for acute heart failure syndromes? Heart Fail Rev. [Epub ahead of print] PubMed PMID: 19238540

52. Gheorghiade M, Blair JE, Filippatos GS, Macarie C, Ruzyllo W, Korewicki J, Bubenek-Turconi SI, Ceracchi M, Bianchetti M, Carminati P, Kremastinos D, Valentini G, Sabbah HN, HORIZON-HF Investigators (2008) Hemodynamic, echocardiographic, and neurohormonal effects of istaroxime, a novel intravenous inotropic and lusitropic agent: a randomized controlled trial in patients hospitalized with heart failure. J Am Coll Cardiol 51:2276-2285

53. Shah SJ, Blair JE, Filippatos GS, Macarie C, Ruzyllo W, Korewicki J, Bubenek-Turconi SI, Ceracchi M, Bianchetti M, Carminati P, Kremastinos D, Grzybowski J, Valentini G, Sabbah HN, Gheorghiade M, HORIZON-HF Investigators (2009) Effects of istaroxime on diastolic stiffness in acute heart failure syndromes: results from the hemodynamic, echocardiographic, and neurohormonal effects of istaroxime, a novel intravenous inotropic and lusitropic agent: a randomized controlled trial in patients hospitalized with heart failure (HORIZON-HF) trial. Am Heart J 157:1035-1041

54. Teerlink JR (2009) A novel approach to improve cardiac performance: cardiac myosin activators. Heart Fail Rev. [Epub ahead of print] PubMed PMID: 19234787

55. Fragasso G, Salerno A, Spoladore R, Bassanelli G, Arioli F, Margonato A (2008) Metabolic therapy of heart failure. Curr Pharm Des 14:2582-2591

56. Sabbah HN, Chandler MP, Mishima T, Suzuki G, Chaudhry P, Nass O, Biesiadecki BJ, Blackburn B, Wolff A, Stanley WC (2002) Ranolazine, a partial fatty acid oxidation (pFOX) inhibitor, improves left ventricular function in dogs with chronic heart failure. J Card Fail 8:416-422

57. Rastogi S, Sharov VG, Mishra S, Gupta RC, Blackburn B, Belardinelli L, Stanley WC, Sabbah HN (2008) Ranolazine combined with enalapril or metoprolol prevents progressive LV dysfunction and remodeling in dogs with moderate heart failure. Am J Physiol Heart Circ Physiol 295:H2149-H2155

58. Tuunanen H, Engblom E, Naum A, Någren K, Scheinin M, Hesse B, Juhani Airaksinen KE, Nuutila P, Iozzo P, Ukkonen H, Opie LH, Knuuti J (2008) Trimetazidine, a metabolic modulator, has cardiac and extracardiac benefits in idiopathic dilated cardiomyopathy. Circulation 118:1250-1258

59. Phan TT, Shivu GN, Choudhury A, Abozguia K, Davies C, Naidoo U, Ahmed I, Yousef Z, Horowitz J, Frenneaux M (2009) Multi-centre experience on the use of perhexiline in chronic heart failure and refractory angina: old drug, new hope. Eur J Heart Fail 11:881-886

60. Hajjar RJ, Zsebo K, Deckelbaum L, Thompson C, Rudy J, Yaroshinsky A, Ly H, Kawase Y, Wagner K, Borow K, Jaski B, London B, Greenberg B, Pauly DF, Patten R, Starling R, Mancini D, Jessup M (2008) Design of a phase $1 / 2$ trial of intracoronary administration of AAV1/SERCA2a in patients with heart failure. J Card Fail 14:355-367

61. Jaski BE, Jessup ML, Mancini DM, Cappola TP, Pauly DF, Greenberg B, Borow K, Dittrich H, Zsebo KM, Hajjar RJ, Calcium Up-Regulation by Percutaneous Administration of Gene Therapy In Cardiac Disease (CUPID) Trial Investigators (2009) Calcium upregulation by percutaneous administration of gene therapy in cardiac disease (CUPID Trial), a first-in-human phase 1/2 clinical trial. J Card Fail 15:171-181 